\title{
Synthesis and Characterization of New Comb-Like Polyguanamines Containing Three Long Alkyl Side-Chains in Repeating Unit
}

\author{
Jui-Kun LIN, Yasuo YUKI, ${ }^{*}$ Hideo KUNISADA, \\ and Shuji KONDO \\ Department of Materials Science and Engineering, \\ Nagoya Institute of Technology, Gokiso-cho, \\ Showa-ku, Nagoya 466, Japan
}

(Received September 11, 1989)

\begin{abstract}
Novel comb-like poly(amide-guanamine)s, poly(urea-guanamine)s and poly(imide-guanamine)s which contain three long alkyl side-chains in each repeating unit (three sidechains polymers), were synthesized by the reaction of 2,4-bis(amino- $N$-octadecylanilino)-6-heptadecyl-1,3,5-triazines with aromatic or aliphatic diacid chlorides, diisocyanates and pyromellitic dianhydride, respectively. Making reference to the three side-chain polymers, the corresponding one side-chain polymers were also prepared using 2,4-bis(aminoanilino)-6-heptadecyl-1,3,5triazine as a monomer. Although the one side-chain polymers were insoluble in tetrahydrofuran, chloroform, toluene and benzene, the three side-chains polymers except polyimides were readily soluble in these solvents. These polymers had good thermal stability though the bulky long alkyl groups were present. The three side-chains polymers are characterized by side-chain crystallinity. The one side-chain polymers were found to show low crystallinity by differential scanning calorimetry and wide angle $\mathrm{X}$-ray diffraction. The influence of the main-chain structure on the sidechain crystallization was investigated.
\end{abstract}

KEY WORDS Comb-Like Polymer / 1,3,5-Triazine / Long Alkyl Group Poly(amide-guanamine) / Poly(urea-guanamine) / Poly(imide-guanamine) Side-Chain Crystallization /

Comb-like polymers containing rigid mainchain and flexible long alkyl side-chains have attracted great interest because this specific combination is expected to lead to a favorable property. ${ }^{1-5}$ For example, $N$-octadecylated poly ( $p$-phenylene terephthalamide) containing the rigid backbone and flexible alkyl sidechains shows side-chain crystallization and liquid crystalline behavior of the lyotropic type. For dynamic mechanical properties, two characteristic relaxations were observed, and assigned to the crystalline and amorphous phase of the side-chains, respectively. ${ }^{3}$

In previous papers of this series ${ }^{6-9}$ we investigated the properties of several aromatic comb-like polymers prepared from diamines containing 1,3,5-triazine ring with one $\left(\mathbf{I}^{6}\right)$ or two long alkyl groups $\left(\mathbf{I I},{ }^{7} \mathbf{I I I}^{8}\right.$ and $\left.\mathbf{I V}^{9}\right)$.

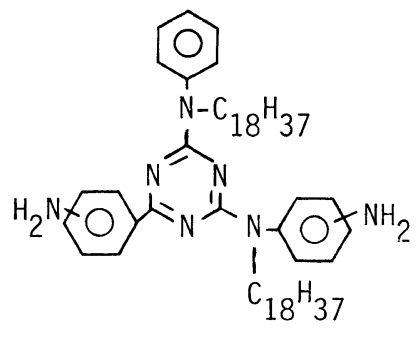




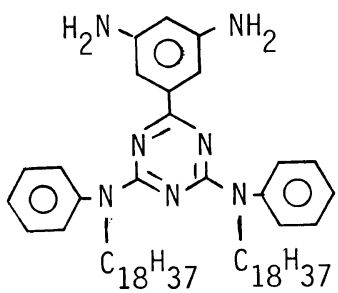

III

Compared with unsubstituted polymers, the polymers containing two long alkyl groups in the repeating unit gave an obvious change in solubilities, but the one side-chain polymers showed only little change. Both one and two side-chains polymers showed a slight decrease or no change in thermal stabilities by introduction of long alkyl groups. Differential scanning calorimetry has shown that sidechain crystallization occurs in the two sidechains polymers, but one side-chain polymers had low crystallinity.

In the present paper, two new diamines with three long alkyl groups, 2,4-bis(amino- $N$ octadecylanilino)-6-heptadecyl-1,3,5-triazines [3] and [4], were prepared by the alkylation of 2,4-bis(aminoanilino)-6-heptadecyl-1,3,5triazines [1] and [2].

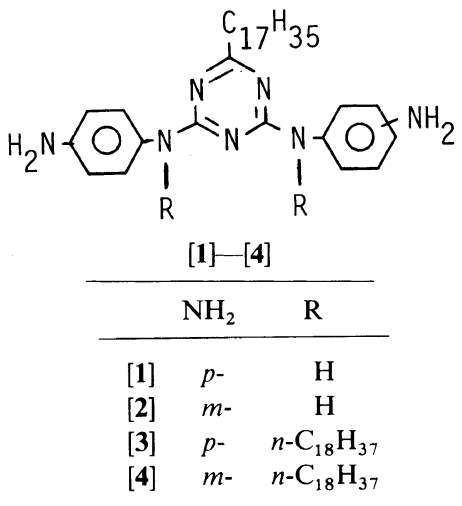

A series of new type comb-like polyamides, polyureas and polyimides were prepared from [1]-[4] and aromatic or aliphatic comonomers. The influence of long alkyl groups on solubilities and thermal properties for these polymers was investigated, and the side-chain

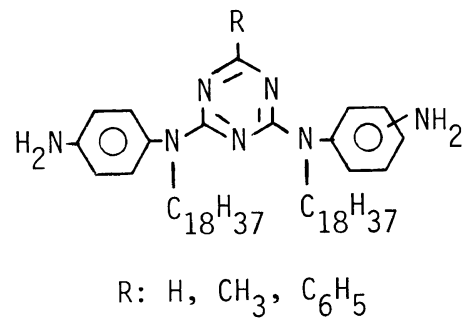

IV

crystallization of these polymers is also discussed.

\section{EXPERIMENTAL}

\section{Materials and Monomers}

Terephthaloyl chloride (TC), isophthaloyl chloride (IC), sebacoyl chloride (SC), 4,4'diphenylmethane diisocyanate (MI), 2,4-toluene diisocyanate (TI), hexamethylene diisocyanate (HI) and pyromellitic dianhydride (PA) were commercially obtained. Solvents such as tetrahydrofuran (THF), $N, N$-dimethylacetamide (DMAc), $N$-methyl-2-pyrrolidone (NMP) and dimethyl sulfoxide (DMSO) were purified by distillation.

\section{2-Anilino-4-( p-nitroanilino)-6-heptadecyl- 1,3,5-triazine [5]}

Stearoyl chloride $(30.3 \mathrm{~g}, 0.10 \mathrm{~mol})$ was added dropwise to a stirred solution of 1-phenyl5-( $p$-nitrophenyl)biguanide $(32.7 \mathrm{~g}, 0.11 \mathrm{~mol})$ and triethylamine $(15.2 \mathrm{~g}, 0.15 \mathrm{~mol})$ in $300 \mathrm{ml}$ of acetone at $40^{\circ} \mathrm{C}$. This mixture was separated after $6 \mathrm{~h}$ of stirring, and the filtrate was poured into a dilute aqueous solution of sodium hydroxide. The precipitated product was separated and washed thoroughly with water. Recrystallization from 2-methoxyethanol gave $45.2 \mathrm{~g}(82.5 \%)$ of [5], mp $96^{\circ} \mathrm{C}$. Anal. Found: C, $70.10 \%$; H, 9.07\% $\mathrm{N}, 15.45 \%$. Calcd for $\mathrm{C}_{32} \mathrm{H}_{46} \mathrm{~N}_{6} \mathrm{O}_{2}: \mathrm{C}, 70.30 \% ; \mathrm{H}, 8.48 \% ; \mathrm{N}$, $15.37 \%$.

\section{2-Anilino-4-(m-nitroanilino)-6-heptadecyl- 1,3,5-triazine [6]}

[6] was prepared by the reaction of 1-phen- 
yl-5-( $m$-nitrophenyl)biguanide and stearoyl chloride in a similar method for [5] and recrystallized from ethanol. Yield $75 \%, \mathrm{mp}$ $73^{\circ}$ C. Anal. Found: C, 69.75\%; H, 8.44\%; N, $15.15 \%$. Calcd for $\mathrm{C}_{32} \mathrm{H}_{46} \mathrm{~N}_{6} \mathrm{O}_{2}: \mathrm{C}, 70.30 \%$; $8.48 \% ; \mathrm{N}, 15.37 \%$.

\section{2,4-Bis( p-nitroanilino)-6-heptadecyl-1,3,5-tri- azine [7]}

[7] was prepared by the nitration of [5] with $\mathrm{KNO}_{3}-\mathrm{H}_{2} \mathrm{SO}_{4}$ according to the literature method $^{10,11}$ and recrystallized from 2-methoxyethanol. Yield $92 \%, \mathrm{mp} 223^{\circ} \mathrm{C}$. Anal. Found: C, 64.74\% H, 7.60\% N, $16.51 \%$. Calcd for $\mathrm{C}_{32} \mathrm{H}_{45} \mathrm{~N}_{7} \mathrm{O}_{4}$ : C, $64.95 \%$; $\mathrm{H}, 7.67 \%$; N, $16.57 \%$. ${ }^{1} \mathrm{H}$ NMR (DMSO- $d_{6}$ ) $\delta$ ppm: 0.90 $\left(\mathrm{t}, 3 \mathrm{H}, \mathrm{CH}_{3}\right), 1.08-1.65\left(\mathrm{~m}, 30 \mathrm{H}, 15 \mathrm{CH}_{2}\right)$, $2.62\left(\mathrm{t}, 2 \mathrm{H}, \mathrm{CH}_{2}\right.$-triazine $), 8.10(\mathrm{~d}, 4 \mathrm{H}, 2 \mathrm{Ar})$, 8.15 (d, 4H, 2Ar), 10.35 (s, 2H, 2NH).

\section{2-( $p$-Nitroanilino $)-4-(m-n i t r o a n i l i n o)-6-h e p-$} tadecyl-1,3,5-triazine [8]

[8] was prepared by the nitration of [6] in a similar method for [7]. Yield $86 \%, \mathrm{mp} 195^{\circ} \mathrm{C}$. Anal. Found: C, $65.12 \%$; H, $7.79 \%$; N, $16.36 \%$. Calcd for $\mathrm{C}_{32} \mathrm{H}_{45} \mathrm{~N}_{7} \mathrm{O}_{4}$ : C, $64.95 \% ; \mathrm{H}, 7.67 \%$; N, $16.57 \%$. ${ }^{1} \mathrm{H}-\mathrm{NMR}$ (DMSO- $d_{6}$ ) $\delta$ ppm: 0.85 $\left(\mathrm{t}, 3 \mathrm{H}, \mathrm{CH}_{3}\right), 1.08-1.72\left(\mathrm{~m}, 30 \mathrm{H}, 15 \mathrm{CH}_{2}\right)$, 2.62 (t, 2H, $\mathrm{CH}_{2}$-triazine), 8.07 (s, 4H, p-Ar), $7.50-8.75(\mathrm{~m}, 4 \mathrm{H}, m-\mathrm{Ar}), 10.30(\mathrm{~s}, 1 \mathrm{H}, \mathrm{NH})$, 10.47 (s, 1H, NH).

\section{2,4-Bis( p-aminoanilino)-6-heptadecyl-1,3-5- triazine [1]}

[7] $(20.5 \mathrm{~g}, 0.035 \mathrm{~mol})$ was added to a stirred suspension of ferrous sulfate $(20 \mathrm{~g})$ and iron powder $(80 \mathrm{~g})$ in ethanol $(300 \mathrm{ml})$, DMSO (50 $\mathrm{ml})$ and water $(70 \mathrm{ml})$. The suspention was separated after $6 \mathrm{~h}$ of stirring and refluxing at $85^{\circ} \mathrm{C}$. The filtrate was poured into a large amount of ice-water. The precipitated product was separated and recrystallized from 2-methoxyethanol to give $16.3 \mathrm{~g}(90 \%)$ of [1], mp $130^{\circ}$ C. Anal. Found: C, $71.74 \% ; \mathrm{H}, 9.68 \%$; N, $18.40 \%$. Calcd for $\mathrm{C}_{32} \mathrm{H}_{49} \mathrm{~N}_{7}: \mathrm{C}, 72.27 \% ; \mathrm{H}$, $9.29 \%$; N, $18.44 \%$. ${ }^{1} \mathrm{H}$ NMR (DMSO- $d_{6}$ ) $\delta$ ppm: $0.86\left(\mathrm{t}, 3 \mathrm{H}, \mathrm{CH}_{3}\right), 1.08-1.74(\mathrm{~m}, 30 \mathrm{H}$, $\left.15 \mathrm{CH}_{2}\right), 2.51\left(\mathrm{t}, 2 \mathrm{H}, \mathrm{CH}_{2}\right.$-triazine), 4.64 (br s, $\left.4 \mathrm{H}, 2 \mathrm{NH}_{2}\right), 6.55(\mathrm{~d}, 4 \mathrm{H}, 2 \mathrm{Ar}), 7.39(\mathrm{~d}, 4 \mathrm{H}$, 2Ar), 9.06 (s, 2H, 2NH).

\section{2-( $p$-Aminoanilino $)-4-(m-$ aminoanilino $)-6-$ heptadecyl-1,3,5-triazine [2]}

[2] was prepared by the reduction of [8] in a similar method for [1]. Yield $92 \%, \mathrm{mp} 106^{\circ} \mathrm{C}$. Anal. Found: C, $71.78 \%$; H, 9.39\%, N, 18.14\%. Calcd for $\mathrm{C}_{32} \mathrm{H}_{49} \mathrm{~N}_{7}$ : C, $72.27 \% ; \mathrm{H}, 9.29 \%$; N, $18.44 \% .{ }^{1} \mathrm{H}-\mathrm{NMR}$ (DMSO- $\left.d_{6}\right) \delta \mathrm{ppm}: 0.88(\mathrm{t}$, $\left.3 \mathrm{H}, \mathrm{CH}_{3}\right), 1.04-1.70\left(\mathrm{~m}, 30 \mathrm{H}, 15 \mathrm{CH}_{2}\right), 2.50$ (t, 2H, $\mathrm{CH}_{2}$-triazine), 4.72 (brs, $4 \mathrm{H}, 2 \mathrm{NH}_{2}$ ), $6.38(\mathrm{~m}, 1 \mathrm{H}, \mathrm{m}-\mathrm{Ar}), 6.57(\mathrm{~d}, 2 \mathrm{H}, p-\mathrm{Ar}), 7.02$ (m, 3H, m-Ar), 7.43 (d, 2H, p-Ar), $9.10(\mathrm{~s}, 1 \mathrm{H}$, NH), 9.17 (s, 1H, NH).

\section{2,4-Bis( p-amino- $N$-octadecylanilino)-6-hep- tadecyl-1,3,5-triazine [3]}

[1] $(8.0 \mathrm{~g}, 0.015 \mathrm{~mol})$ was added to a stirred solution of sodium hydride $(1.32 \mathrm{~g} 0.033 \mathrm{~mol}$; $60 \%$ oil suspension) in $250 \mathrm{ml}$ of DMSO at $50^{\circ} \mathrm{C}$. After $1 \mathrm{~h}$, octadecyl bromide $(10.0 \mathrm{~g}$, $0.03 \mathrm{~mol}$ ) was added to this solution. The mixture was stirred at $50^{\circ} \mathrm{C}$ for $6 \mathrm{~h}$. The precipitated product was separated, washed with water and recrystallized from hexane-benzene ( $8: 2$ volume) to give $12.25 \mathrm{~g}(79 \%)$ of [3], mp $70^{\circ} \mathrm{C}$. Anal. Found: C, 78.94\%; H, $11.98 \%$; N, $9.30 \%$. Calcd for $\mathrm{C}_{68} \mathrm{H}_{121} \mathrm{~N}_{7}: \mathrm{C}, 78.78 \% ; \mathrm{H}$, $11.76 \%$;, $9.46 \% .{ }^{1} \mathrm{H}$ NMR $\left(\mathrm{CDCl}_{3}\right) \delta \mathrm{ppm}$ : $0.87\left(\mathrm{~m}, 9 \mathrm{H}, 3 \mathrm{CH}_{3}\right), 1.02-1.80(\mathrm{~m}, 94 \mathrm{H}$, $\left.47 \mathrm{CH}_{2}\right), 2.40\left(\mathrm{~m}, 2 \mathrm{H}, \mathrm{CH}_{2}\right.$-triazine), $3.63(\mathrm{~s}$, $4 \mathrm{H}, 2 \mathrm{NH}_{2}$ ), 3.91 (brs, $\left.4 \mathrm{H}, 2 \mathrm{NCH}_{2}\right), 6.65$ (d, $4 \mathrm{H}, 2 \mathrm{Ar}), 7.04$ (d, 4H, 2Ar).

2-( $p$-Amino- $N$-octadecylanilino $)-4-(m$-amino$N$-octadecylanilino)-6-heptadecyl-1,3,5-triazine [4]

[4] was prepared by the alkylation of [2] with octadecyl bromide in a similar method for [3]. Yield $82 \%$, mp $98^{\circ} \mathrm{C}$. Anal. Found: C, $79.03 \%$; $\mathrm{H}, 12.00 \%$; N $9.33 \%$. Calcd for $\mathrm{C}_{68} \mathrm{H}_{121} \mathrm{~N}_{7}: \mathrm{C}$, $78.78 \% ; \mathrm{H}, 11.76 \% ; \mathrm{N}, 9.46 \% .{ }^{1} \mathrm{H}$ NMR $\left(\mathrm{CDCl}_{3}\right) \delta$ ppm: $0.88\left(\mathrm{~m}, 9 \mathrm{H}, 3 \mathrm{CH}_{3}\right), 1.04-$ 
$1.92\left(\mathrm{~m}, 94 \mathrm{H}, 47 \mathrm{CH}_{2}\right), 2.48\left(\mathrm{~m}, 2 \mathrm{H}, \mathrm{CH}_{2}-\right.$ triazine $), \quad 3.30-4.42\left(\mathrm{~m}, 8 \mathrm{H}, 2 \mathrm{NH}_{2}\right.$ and $\left.2 \mathrm{NCH}_{2}\right), 6.54$ (m, 3H, m-Ar), 6.62 (d, 2H, pAr), 7.02 (d, 2H, p-Ar), 7.25 (brs, 1H, m-Ar).

\section{Polymerization}

Poly(amide-guanamine) [1]-TC. TC $(0.406 \mathrm{~g}$, $2.0 \mathrm{mmol})$ was added to a stirred solution of [1] $(1.064 \mathrm{~g}, 2.0 \mathrm{mmol})$ in $10 \mathrm{ml}$ of DMAc at room temperature under a nitrogen atmosphere. The solution was stirred for $24 \mathrm{~h}$ and poured into $300 \mathrm{ml}$ of methanol. The precipitated polymer was separated, washed thoroughly with methanol and dried in vacuo. Yield was $1.24 \mathrm{~g}(95 \%)$. [1]-TC was purified by reprecipitation from DMAc into methanol. Anal. Found: C, $72.28 \%, \mathrm{H}, 7.74 \%, \mathrm{~N}$, $14.57 \%$. Calcd for $\mathrm{C}_{40} \mathrm{H}_{51} \mathrm{~N}_{7} \mathrm{O}_{2}: \mathrm{C}, 72.58 \%, \mathrm{H}$, $7.76 \%$, N, $14.81 \%$.

Poly(amide-guanamine) [3]-TC. [3] (1.037 $\mathrm{g}, 1.0 \mathrm{mmol})$ was dissolved in $10 \mathrm{ml}$ of THF-NMR (2:1 volume) with stirring, and TC $(0.203 \mathrm{~g}, 1.0 \mathrm{mmol})$ was added to this solution at room temperature. The precipitated polymer was separated, washed thoroughly with methanol and dried in vacuo. Yield was $1.09 \mathrm{~g}(93 \%)$. Reprecipitation of [3]-TC was carried out from THF into acetone. Anal. Found: C, $77.23 \%, \mathrm{H}, 10.68 \%, \mathrm{~N}, 8.30 \%$. Calcd for $\mathrm{C}_{76} \mathrm{H}_{123} \mathrm{~N}_{7} \mathrm{O}_{2}: \mathrm{C}, 78.23 \%, \mathrm{H}$, $10.62 \%$, N, $8.40 \%$.

Poly(urea-guanamine) [1]-MI. MI $(0.50 \mathrm{~g}$, $2.0 \mathrm{mmol}$ ) was added to a stirred solution of [1] $(1.064 \mathrm{~g}, 2.0 \mathrm{mmol})$ in $10 \mathrm{ml}$ of DMAc at room temperature. The solution was stirred at room temperature for $6 \mathrm{~h}$ and at $60^{\circ} \mathrm{C}$ for $2 \mathrm{~h}$, and poured into $300 \mathrm{ml}$ of methanol to give $1.58 \mathrm{~g}$ $(99 \%)$ of [1]-MI. Reprecipitation of [1]-MI was carried out from DMAc into methanol. Anal. Found: C, $71.98 \%, \mathrm{H}, 7.68 \%, \mathrm{~N}$, $16.34 \%$. Calcd for $\mathrm{C}_{47} \mathrm{H}_{59} \mathrm{~N}_{9} \mathrm{O}_{2}: \mathrm{C}, 72.18 \%, \mathrm{H}$, $7.60 \%, \mathrm{~N}, 16.12 \%$.

Poly(urea-guanamine) [3]-MI. MI (0.250 g, $1.0 \mathrm{mmol}$ ) was added to a stirred solution of [1] $(1.037 \mathrm{~g}, 1.0 \mathrm{mmol})$ in $10 \mathrm{ml}$ of THF-NMP (2:1 volume) at room temperature. The so- lution was stirred at room temperature for $6 \mathrm{~h}$ and at $60^{\circ} \mathrm{C}$ for $2 \mathrm{~h}$, and poured into $300 \mathrm{ml}$ of methanol to give $1.28 \mathrm{~g}(99 \%)$ of [3]-MI. Reprecipitation of [3]-MI was carried out from THF into acetone. Anal. Found: C, $77.71 \%, \mathrm{H}, 10.66 \%, \mathrm{~N}, 9.57 \%$. Calcd for $\mathrm{C}_{83} \mathrm{H}_{131} \mathrm{~N}_{9} \mathrm{O}_{2}: \mathrm{C}, 77.46 \%, \mathrm{H}, 10.26 \%, \mathrm{~N}$, $9.79 \%$.

Poly(imide-guanamine) [1]-PI. PA $(0.4360 \mathrm{~g}$, $2.0 \mathrm{mmol}$ ) was added to a stirred solution of [1] $(1.064 \mathrm{~g}, 2.0 \mathrm{mmol})$ in $10 \mathrm{ml}$ of NMP at room temperature. The solution was stirred at room temperature for $24 \mathrm{~h}$ and poured into $300 \mathrm{ml}$ of methanol to give $1.38 \mathrm{~g}(92 \%)$ of poly(amic acid-guanamine) [1]-PA. Reprecipitation of [1]-PA was carried out from DMAc into methanol. Anal. Found: C, 66.35\%, H, 6.91\%, $\mathrm{N}, 12.62 \%$. Calcd for $\mathrm{C}_{42} \mathrm{H}_{51} \mathrm{~N}_{7} \mathrm{O}_{6}: \mathrm{C}, 67.27 \%$, $\mathrm{H}, 6.85 \%$, N, $13.07 \%$. [1]-PI was then prepared by heating [1]-PA at $200^{\circ} \mathrm{C}$ for $6 \mathrm{~h}$ in vacuo. Anal. Found: C, 70.77\%, H, 6.99\%, $\mathrm{N}, 14.28 \%$. Calcd for $\mathrm{C}_{42} \mathrm{H}_{47} \mathrm{~N}_{7} \mathrm{O}_{4}: \mathrm{C}, 70.75 \%$, $\mathrm{H}, 6.65 \%, \mathrm{~N}, 13.75 \%$.

Poly(imide-guanamine) [3]-PI. PA $(0.218 \mathrm{~g}$, $1.0 \mathrm{mmol})$ was added to a stirred solution of [3] $(1.037 \mathrm{~g}, 1.0 \mathrm{mmol})$ in $10 \mathrm{ml}$ of $\mathrm{THF}-\mathrm{NMP}$ ( $2: 1$ volume) at room temperature. The solution was stirred at room temperature for $24 \mathrm{~h}$, and poured into $300 \mathrm{ml}$ of methanol to give $1.22 \mathrm{~g}(97 \%)$ of poly(amic acidguanamine) [3]-PA. Reprecipitation of [3]-PA was carried out from THF into acetone. Anal. Found: C, $74.16 \%, \mathrm{H}, 9.92 \%, \mathrm{~N}, 7.74 \%$. Calcd for $\mathrm{C}_{78} \mathrm{H}_{123} \mathrm{~N}_{7} \mathrm{O}_{6}: \mathrm{C}, 74.65 \%, \mathrm{H}, 9.98 \%, \mathrm{~N}$, $7.81 \%$. [3]-PI was then prepared by heating [3]-PA at $200^{\circ} \mathrm{C}$ for $6 \mathrm{~h}$ in vacuo. Anal. Found: C, $76.20 \%, \mathrm{H}, 9.68 \%, \mathrm{~N}, 7.72 \%$. Calcd for $\mathrm{C}_{78} \mathrm{H}_{119} \mathrm{~N}_{7} \mathrm{O}_{4}: \mathrm{C}, \quad 76.86 \%, \mathrm{H}, 9.84 \%, \mathrm{~N}$, $8.04 \%$.

Other poly(amide-guanamine)s, poly(ureaguanamine)s, and poly(imide-guanamine)s were prepared in a similar manner.

\section{Measurements}

IR and ${ }^{1} \mathrm{H}$ NMR spectra were recorded on a Hitachi 285 spectrophotometer and Hitachi 
R600 FTNMR $(60 \mathrm{MHz})$ spectrometer, respectively. Thermogravimetry and differential thermal analysis were performed with a Rigaku TG-DTA 812BH thermal analysis system. A Rigaku DSC 8131BL differential scanning calorimeter was used to study the sidechain crystallization of polymers. X-ray diffraction patterns were recorded with solid samples using $\mathrm{Cu}-K_{\alpha}$ radiation on a Rigaku Cat. 4032A2 diffractometer. Reduced viscosities were measured using an Ostwald viscometer.

\section{RESULTS AND DISCUSSION}

\section{Synthesis of Diamines}

2,4-Bis ( $p$ - or $m$-aminoanilino)-6-heptadecyl1,3,5-triazines [1] and [2] were prepared by the reaction of 1-phenyl-5-( $p$ - or $m$-nitrophenyl)biguanide with stearoyl chloride, followed by the nitration with $\mathrm{KNO}_{3}-\mathrm{H}_{2} \mathrm{SO}_{4}$ and then the reduction with $\mathrm{Fe}-\mathrm{FeSO}_{4} .2,4-$ $\operatorname{Bis}(p$ - or $m$-amino- $N$-octadecylanilino)-6-hep- tadecyl-1,3,5-triazines [3] and [4] were prepared by the alkylation of [1] and [2] with octadecyl bromide using sodium hydride (Scheme 1). The structures of diamines [1]-[4] were confirmed by IR, ${ }^{1} \mathrm{H}$ NMR and elemental analysis.

\section{Synthesis of Polymers}

Poly(amide-guanamine)s: The one sidechain poly(amide-guanamine)s, [1]-TC-[2]$\mathrm{SC}$ and three side-chains poly(amide-guanamine)s, [3]-TC-[4]-SC, which contain one or three long alkyl side-chains in the repeating units, were prepared by the polycondensation of [1], [2], [3], and [4] with aromatic TC, IC, or aliphatic diacid chloride SC, respectively (Scheme 2). All the reactions proceeded homogeneously and gave polymers almost quantitavely. The results are listed in Table I. These poly(amide-guanamine)s had reduced viscosities in the range of $0.22-0.46$ $\mathrm{dl} \mathrm{g}^{-1}$

Poly(urea-guanamine)s: The one and three side-chains poly(urea-guanamine)s, [1]-MI-

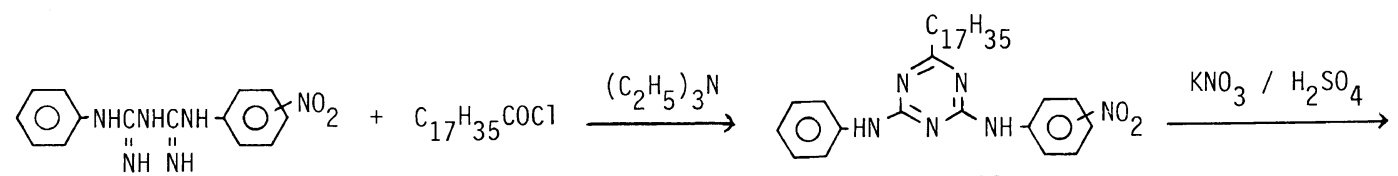

$$
\begin{aligned}
& \text { [5]; } p-\mathrm{NO}_{2} \\
& \text { [6]; } m-\mathrm{NO}_{2}
\end{aligned}
$$

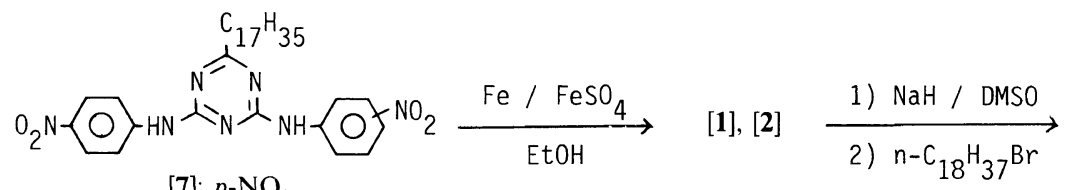

[3], [4]

[7]; $p-\mathrm{NO}_{2}$

[8]; $m-\mathrm{NO}_{2}$

Scheme 1.

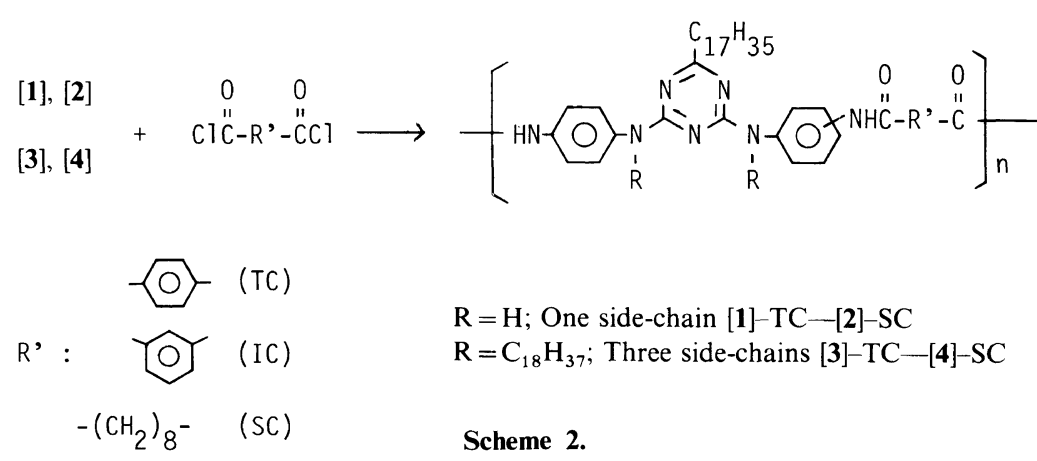


[2]-HI and [3]-MI- - 44]-HI, were prepared by the polyaddition of [1]-[4] with aromatic MI, TI, or aliphatic diisocyanates HI (Scheme 3). The reactions proceeded in a homogeneous solution and afforded the polymers in quantitative yield. The results are listed in Table II. These poly(urea-guanamine)s had reduced viscosities in the range of $0.24 \quad 0.62 \mathrm{dlg}^{-1}$.

Poly(imide-guanamine)s: The poly(imideguanamine)s [1]-PI-[4]-PI were prepared by a two-step procedure (Scheme 4). In the first step, the polyamic acids [1]-PA-[4]-PA were prepared by the reaction of [1]-[4] with PA. The reactions proceeded in a homogeneous solution. In the second step, [1]-PI-[4]-PI were obtained by the thermal cyclodehydration of the corresponding polyamic acid at $200^{\circ} \mathrm{C}$ in vacuo. The results are listed in Table III.

The structures of these polymers were confirmed by elemental analysis and IR spectra. The results of elemental analysis agreed with the calculated values. The IR spectra of the poly(amide-guanamine)s showed typical absorptions of amides at 3350 and $1650 \mathrm{~cm}^{-1}$. Poly(urea-guanamine)s also showed absorption bands at 3300 and $1650 \mathrm{~cm}^{-1}$. Polyamic acids showed absorption bands at 3350, 1720

Table I. Preparation of comb-like poly(amide-guanamine)s

\begin{tabular}{|c|c|c|c|c|c|}
\hline Polymer & $\mathbf{R}$ & Solvent & $\frac{\text { Yield }}{\%}$ & $\frac{\eta_{\mathrm{sp}} / c}{\mathrm{dl} \mathrm{g}^{-1}}$ & $\frac{T_{\mathrm{d}}^{\mathrm{c}}}{{ }^{\circ} \mathrm{C}}$ \\
\hline$[1]-\mathrm{TC}$ & $\mathrm{H}$ & DMAc & 95 & $0.26^{\mathrm{a}}$ & 443 \\
\hline [1]-IC & $\mathrm{H}$ & DMAc & 99 & $0.27^{\mathrm{a}}$ & 428 \\
\hline$[1]-S C$ & $\mathbf{H}$ & DMAc & 76 & $0.23^{\mathrm{a}}$ & 425 \\
\hline [2]-TC & $\mathrm{H}$ & DMAc & 96 & $0.31^{\mathrm{a}}$ & 425 \\
\hline [2]-IC & $\mathrm{H}$ & DMAc & 95 & $0.22^{\mathrm{a}}$ & 415 \\
\hline [2]-SC & $\mathrm{H}$ & DMAc & 80 & $0.25^{\mathrm{a}}$ & 405 \\
\hline [3]-TC & $\mathrm{C}_{18} \mathrm{H}_{37}$ & THF-NMP $(2: 1)$ & 93 & $0.23^{b}$ & 422 \\
\hline [3]-IC & $\mathrm{C}_{18} \mathrm{H}_{37}$ & THF-NMP $(2: 1)$ & 93 & $0.28^{b}$ & 407 \\
\hline [3]-SC & $\mathrm{C}_{18} \mathrm{H}_{37}$ & THF-NMP $(2: 1)$ & 90 & $0.33^{\mathrm{b}}$ & 405 \\
\hline [4]-TC & $\mathrm{C}_{18} \mathrm{H}_{37}$ & THF-NMP $(2: 1)$ & 99 & $0.42^{b}$ & 420 \\
\hline [4]-IC & $\mathrm{C}_{18} \mathrm{H}_{37}$ & THF-NMP $(2: 1)$ & 99 & $0.46^{\mathrm{b}}$ & 405 \\
\hline [4]-SC & $\mathrm{C}_{18} \mathrm{H}_{37}$ & THF-NMP $(2: 1)$ & 86 & $0.38^{\mathrm{b}}$ & 415 \\
\hline
\end{tabular}

a Measured in DMAc at $30^{\circ} \mathrm{C}, c=0.2 \mathrm{~g} \mathrm{dl}^{-1}$.

b Measured in THF-NMP $(3: 1)$ at $30^{\circ} \mathrm{C}, c=0.2 \mathrm{~g} \mathrm{dl}^{-1}$.

c Decomposition temperature at which $5 \%$ weight loss was recorded by TG at a heating rate of $10^{\circ} \mathrm{C} \mathrm{min}^{-1}$ in air.

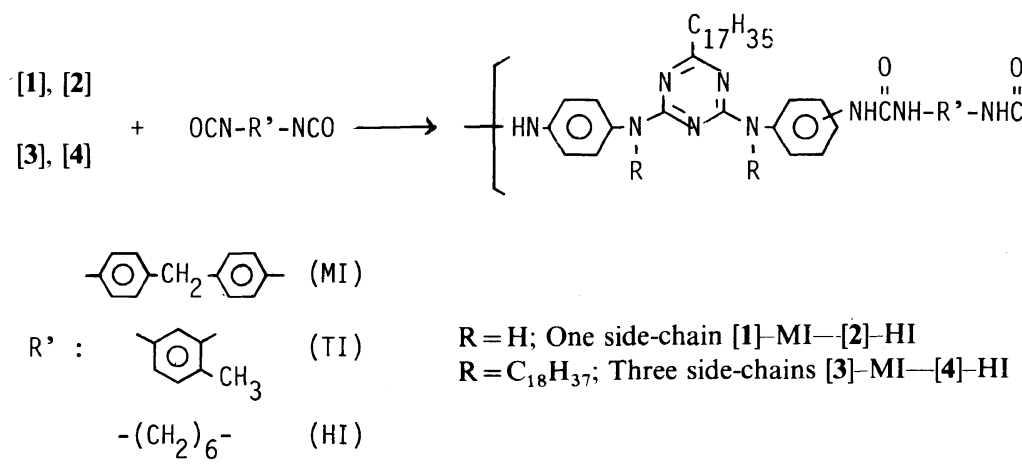

Scheme 3. 
Table II. Preparation of comb-like poly(urea-guanamine)s

\begin{tabular}{|c|c|c|c|c|c|}
\hline \multirow{2}{*}{ Polymer } & \multirow{2}{*}{$\mathrm{R}$} & \multirow{2}{*}{ Solvent } & \multirow{2}{*}{$\frac{\text { Yield }}{\%}$} & \multirow{2}{*}{$\frac{\eta_{\mathrm{sp}} / c}{\mathrm{dl} \mathrm{g}^{-1}}$} & \multirow{2}{*}{$\frac{T_{\mathrm{d}}^{\mathrm{c}}}{{ }^{\circ} \mathrm{C}}$} \\
\hline & & & & & \\
\hline [1]-MI & $\mathbf{H}$ & DMAc & 96 & $0.42^{\mathrm{a}}$ & 323 \\
\hline [1]-TI & $\mathrm{H}$ & DMAc & 96 & $0.32^{\mathrm{a}}$ & 290 \\
\hline$[1]-\mathrm{HI}$ & $\mathrm{H}$ & DMAc & 96 & $0.37^{\mathrm{a}}$ & 310 \\
\hline [2]-MI & $\mathrm{H}$ & DMAc & 98 & $0.57^{\mathrm{a}}$ & 315 \\
\hline [2]-TI & $\mathrm{H}$ & DMAc & 98 & $0.35^{\mathrm{a}}$ & 280 \\
\hline$[2[-\mathrm{HI}$ & $\mathrm{H}$ & DMAc & 98 & $0.62^{\mathrm{a}}$ & 318 \\
\hline [3]-MI & $\mathrm{C}_{18} \mathrm{H}_{37}$ & THF-NMP $(2: 1)$ & 99 & $0.33^{\mathrm{b}}$ & 310 \\
\hline [3]-TI & $\mathrm{C}_{18} \mathrm{H}_{37}$ & THF-NMP $(2: 1)$ & 99 & $0.32^{\mathrm{b}}$ & 293 \\
\hline [3]-HI & $\mathrm{C}_{18} \mathrm{H}_{37}$ & THF-NMP $(2: 1)$ & 97 & $0.30^{\mathrm{b}}$ & 330 \\
\hline [4]-MI & $\mathrm{C}_{18} \mathrm{H}_{37}$ & THF-NMP $(2: 1)$ & 91 & $0.24^{\mathrm{b}}$ & 325 \\
\hline [4]-TI & $\mathrm{C}_{18} \mathrm{H}_{37}$ & THF-NMP $(2: 1)$ & 99 & $0.26^{\mathrm{b}}$ & 290 \\
\hline [4]-HI & $\mathrm{C}_{18} \mathrm{H}_{37}$ & THF-NMP $(2: 1)$ & 95 & $0.25^{\mathrm{b}}$ & 335 \\
\hline
\end{tabular}

a Measured in DMAc at $30^{\circ} \mathrm{C}, c=0.2 \mathrm{~g} \mathrm{dl}^{-1}$.

b Measured in THF-NMP $(3: 1)$ at $30^{\circ} \mathrm{C}, c=0.2 \mathrm{~g} \mathrm{dl}^{-1}$.

c Decomposition temperature at which $5 \%$ weight loss was recorded by TG at a heating rate of $10^{\circ} \mathrm{C} \mathrm{min}^{-1}$ in air.<smiles>[R]N(c1ccc(CC)cc1)c1nc(N([R])c2ccc(NC(=O)c3cc(C(=O)O)c(NC(=O)C(C)(C)CC)cc3C(=O)O)cc2)nc(C([Y15])(C)C)n1</smiles>

[1]-PA-[4]-PA

$\mathrm{R}=\mathrm{H}$; One side-chain [1] $-\mathrm{PA}$ and [2]-PA

$\mathrm{R}=\mathrm{C}_{18} \mathrm{H}_{37}$; Three side-chains [3]-PA and [4]-PA

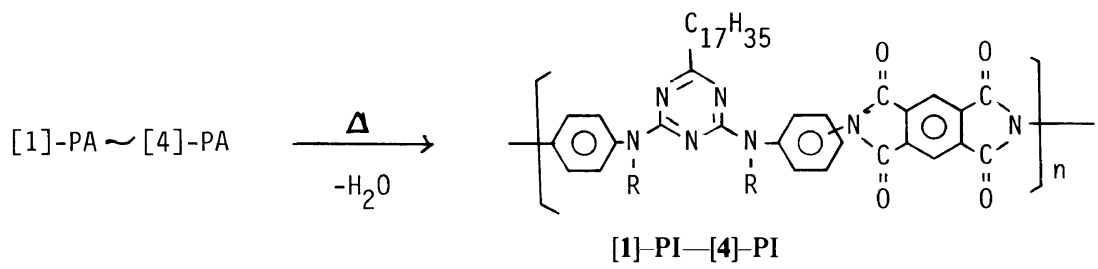

Scheme 4.

and $1660 \mathrm{~cm}^{-1}$, and these bands disappeared after cyclodehydration. New absorptions of imide ring were observed at 1780, 1730 and $1350 \mathrm{~cm}^{-1}$. In addition, all polymers showed characteristic absorption bands for the 1,3,5triazine rings at 1410 and $820 \mathrm{~cm}^{-1}$, and for the octadecyl groups at 2920, 2850 and $720 \mathrm{~cm}^{-1}$.

\section{Characterization of Polymers}

The typical solubility behavior of the polymers derived from [1] and [3] is listed in Table IV. Other polymers also showed similar results. The one side-chain polymers were soluble in polar aprotic solvents such as $N, N$-dimethylformamide, DMAc and NMP. This was also found for corresponding polymers without long alkyl side-chains which 
Table III. Preparation of comb-like polyamic acids and poly(imide-guanamine)s

\begin{tabular}{|c|c|c|c|c|c|}
\hline \multirow{2}{*}{ Polymer } & \multirow{2}{*}{$\mathrm{R}$} & \multirow{2}{*}{ Solvent } & \multirow{2}{*}{$\frac{\text { Yield }}{\%}$} & \multirow{2}{*}{$\frac{\eta_{\mathrm{sp}} / c}{\mathrm{dl} \mathrm{g}^{-1}}$} & \multirow{2}{*}{$\frac{T_{\mathrm{d}}^{\mathrm{c}}}{{ }^{\circ} \mathrm{C}}$} \\
\hline & & & & & \\
\hline [1]-PA & $\mathrm{H}$ & NMP & 90 & $0.31^{\mathrm{a}}$ & \\
\hline [1]-PI & $\mathrm{H}$ & Bulk & 99 & Insol. & 433 \\
\hline [2]-PA & $\mathrm{H}$ & NMP & 95 & $0.26^{\mathrm{a}}$ & \\
\hline [2]-PI & $\mathrm{H}$ & Bulk & 98 & Insol. & 435 \\
\hline [3]-PA & $\mathrm{C}_{18} \mathrm{H}_{37}$ & THF-NMP $(2: 1)$ & 97 & $0.29^{b}$ & \\
\hline [3]-PI & $\mathrm{C}_{18} \mathrm{H}_{37}$ & Bulk & 98 & Insol. & 430 \\
\hline [3]-PA & $\mathrm{C}_{18} \mathrm{H}_{37}$ & THF-NMP $(2: 1)$ & 94 & $0.37^{\mathrm{b}}$ & \\
\hline [4]-PI & $\mathrm{C}_{18} \mathrm{H}_{37}$ & Bulk & 98 & Insol. & 440 \\
\hline
\end{tabular}

a Measured in DMAc at $30^{\circ} \mathrm{C}, c=0.2 \mathrm{~g} \mathrm{dl}^{-1}$.

b Measured in THF-NMP $(3: 1)$ at $30^{\circ} \mathrm{C}, c=0.2 \mathrm{~g} \mathrm{dl}^{-1}$.

c Decomposition temperature at which $5 \%$ weight loss was recorded by TG at a heating rate of $10^{\circ} \mathrm{C} \mathrm{min}-1$ in air.

Table IV. Solubility of polymers ${ }^{\mathrm{a}}$

\begin{tabular}{|c|c|c|c|c|c|c|c|c|c|}
\hline \multirow{2}{*}{ Polymer } & \multicolumn{9}{|c|}{ Solvents ${ }^{b}$} \\
\hline & DMF & DMAc & NMP & DMSO & THF & Chloroform & Toluene & Benzene & $\mathrm{H}_{2} \mathrm{SO}_{4}$ \\
\hline$[1]-\mathrm{TC}$ & \pm & + & ++ & \pm & \pm & - & - & - & \pm \\
\hline [1]-IC & ++ & ++ & ++ & \pm & \pm & - & - & - & \pm \\
\hline [1]-SC & ++ & ++ & ++ & \pm & \pm & - & - & - & \pm \\
\hline [1]-PA & ++ & ++ & ++ & ++ & - & - & - & - & + \\
\hline [1]-PI & - & - & \pm & - & - & - & - & - & \pm \\
\hline [1]-MI & + & ++ & ++ & \pm & - & - & - & - & \pm \\
\hline [1]-TI & ++ & ++ & ++ & \pm & \pm & - & - & - & \pm \\
\hline [1]-HI & + & ++ & ++ & \pm & \pm & - & - & - & \pm \\
\hline [3]-TC & - & \pm & \pm & - & ++ & + & \pm & + & \pm \\
\hline [3]-IC & - & - & \pm & - & ++ & ++ & + & + & \pm \\
\hline [3]-SC & - & - & \pm & - & ++ & ++ & ++ & ++ & \pm \\
\hline [3]-PA & - & \pm & + & - & ++ & ++ & \pm & \pm & \pm \\
\hline [3]-PI & - & - & - & - & + & \pm & \pm & \pm & \pm \\
\hline [3]-MI & - & - & \pm & - & ++ & ++ & + & + & \pm \\
\hline [3]-TI & - & \pm & + & - & ++ & ++ & ++ & ++ & \pm \\
\hline [3]-HI & - & - & - & - & ++ & ++ & ++ & ++ & \pm \\
\hline
\end{tabular}

a $(++)$, soluble at room temperature; $(+)$, soluble at $60^{\circ} \mathrm{C} ;( \pm)$, partially soluble or swelling; $(-)$, insoluble.

b DMF, $N, N$-dimethylformamide; DMAc, $N, N$-dimethylacetamide; DMSO, dimethyl sulfoxide; NMP, $N$-methyl-2pyrrolidone; THF, tetrahydrofuran.

were prepared from 2,4-bis(aminoanilino)-6(unsubstituted, methyl or phenyl)-1,3,5-triazines, ${ }^{10,12)}$ The three side-chains polymers were soluble in THF, chloroform, toluene and benzene but insoluble in polar aprotic solvents. The influence of long alkyl groups on solubility was observed clearly in the three side-chains polymers.
The one side-chain polymers [1]-MI, [1]-HI, and [2]-MI, and [2]-HI which had higher molecular weights could be cast to transparent and tough films from the NMP solutions. The three side-chains polymers [3]-SC, [3]-HI, [4] IC, [4]-SC, and [4]-HI gave transparent and brittle films by the casting method from the chloroform solutions. 
The thermal properties of the comb-like polymers were investigated by TG, DTA, and DSC. Typical TG and DTA curves for one side-chain poly(amide-guanamine) [1]-TC and three side-chains poly(amide-guanamine) [3]TC are shown in Figure 1, and the decomposition temperature $\left(T_{\mathrm{d}}\right)$ data are listed in Tables I, II, and III. These polymers exhibited no weight loss below $250^{\circ} \mathrm{C}$ in their $\mathrm{TG}$ curves. On the other hand, the corresponding polymers without long alkyl groups showed weight loss at about $120^{\circ} \mathrm{C}$, owing the absorbed water by the observation of the TG curve and elemental analysis. ${ }^{10,12}$ Absorbed water was shown absent in these polymers by the results of TG and elemental analysis. This is because these polymers contain a great many hydrophobic long alkyl groups. On the other hand, the Tds of three side-chains polymers were noted to be close to those of the corresponding one side-chain polymers, which were around $410^{\circ} \mathrm{C}$ for poly(amide-guanamine)s, $300^{\circ} \mathrm{C}$ for poly(urea-guanamine)s, and $440^{\circ} \mathrm{C}$ for poly(imide-guanamine)s. Moreover, the analogous two side-chains polymers reported in the preceding paper showed Tds also in the above ranges. ${ }^{9}$ These results indicate that the number of long alkyl side-chains in the repeating unit is almost independent on thermal stability.

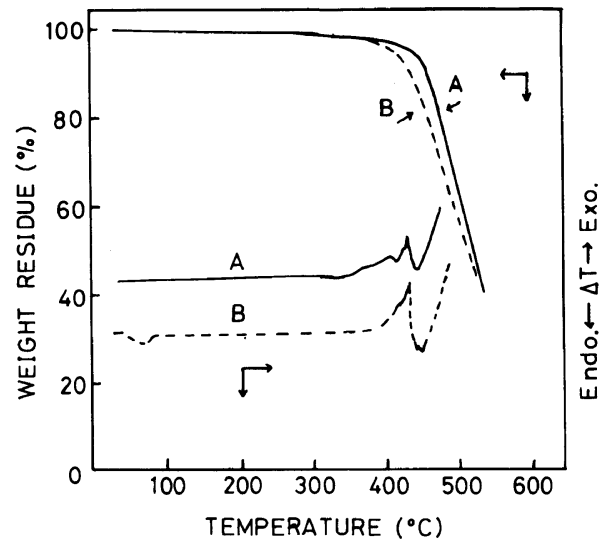

Figure 1. TG and DTA curves of polymers at a heating rate of $10^{\circ} \mathrm{C} \mathrm{min}^{-1}:(\mathrm{A}),[1]-\mathrm{TC} ;(\mathrm{B}),[3]-\mathrm{TC}$.
Figure 2 shows typical X-ray diffraction patterns at room temperature for the powdered polymers. All the one side-chain polymers were found to be almost amorphous as shown in curve $A$. In the three side-chains polymers, the polymers derived from TC, IC and PA showed a broad peak at about $2 \theta=$ $20.7^{\circ}$ (curve B). The poly(urea-guanamine)s derived from MI or TI showed a peak with medium intensity at $2 \theta=21.4^{\circ}$ (curve $\mathrm{C}$ ). The polymers derived from aliphatic $\mathrm{SC}$ or $\mathrm{HI}$ showed a sharp and strong peak at $2 \theta=21.4^{\circ}$ (curve D), corresponding to a spacing of $4.15 \AA$. These peaks agreed with the typical spacing of the hexagonal packing of long alkyl side-chains in the common vinyl comb-like polymers. ${ }^{13-16}$ The hexagonal packing of the long alkyl groups was also proved by a single absorption band at $720 \mathrm{~cm}^{-1}$ in the IR spectrum. ${ }^{17}$

Figure 3 shows typical DSC curves for comblike polymers [1]-SC, [3]-TC, and [4]-SC. The DSC measurements were carried out repeatedly for all polymer samples from -120 to $120^{\circ} \mathrm{C}$ at a rate of $10^{\circ} \mathrm{C} \mathrm{min}^{-1}$. All the one side-chain polymers showed broad-small endothermic and exothermic peaks (curve A). The three side-chains polymer [3]-TC showed

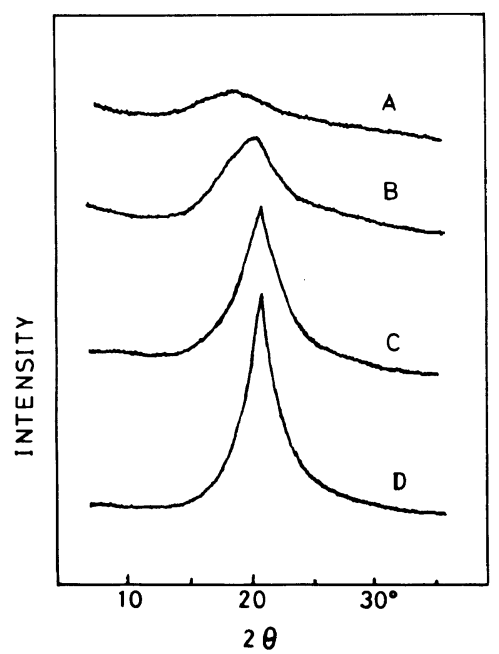

Figure 2. X-Ray diffraction patterns of polymers: (A), [1]-SC; (B), [3]-TC; (C), [4]-MI; (D), [4]-SC. 


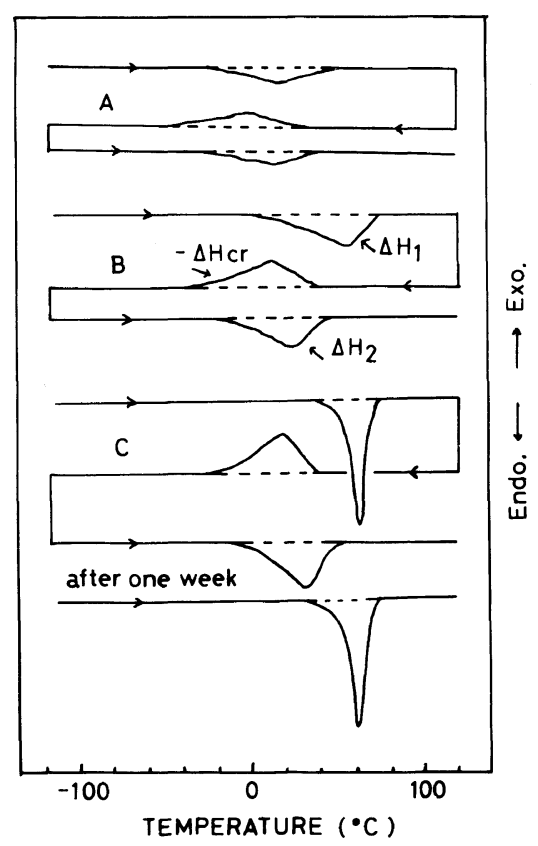

Figure 3. DSC curves of polymers at a heating rate of $10^{\circ} \mathrm{C} \min ^{-1}$ : (A), [1]'SC; (B), [3]-TC; (C), [4]-SC. clear peaks during heating and cooling (curve B). The other polymers derived from the aromatic monomer, IC, PA, MI, and TI, gave similar results. In addition, [4]-SC showed a sharp melting peak in the first heating run, and the peak of reheating run became broad and its melting point was also lower than that of the first heating run. The melting peak of the reheating run reflects the crystals formed by the melting long side-chains under the condition of $10^{\circ} \mathrm{C} \mathrm{min}^{-1}$. When this measured sample was allowed to stand at room temperature for one week, crystals of long alkyl sidechains showed an effective reorganization. The sharpness of the melting peak and position of the melting point of the reorganized sample were found to have resumed those observed in the first heating run (curve $\mathrm{C}$ ). The reflection of X-ray of the reorganized sample was also found to regain its strength. These phenomena were also observed in the other three sidechain polymers derived from the aliphatic SC or HI monomer. However, the reorganization of side-chains for the other polymers was very

Table V. Side-chain crystallization of comb-like polymers ${ }^{\mathrm{a}}$

\begin{tabular}{|c|c|c|c|c|c|c|c|c|c|}
\hline \multirow{3}{*}{ Polymer } & \multirow{2}{*}{\multicolumn{3}{|c|}{$\frac{\begin{array}{c}\text { Melting or } \\
\text { crystallization temp }\end{array}}{{ }^{\circ} \mathrm{C}}$}} & \multirow{2}{*}{\multicolumn{3}{|c|}{$\begin{array}{l}\begin{array}{c}\text { Enthalpy of fusion } \\
\text { or crystallization }\end{array} \\
\mathrm{kcal} \mathrm{mol}^{-1}\end{array}$}} & \multirow{2}{*}{\multicolumn{3}{|c|}{$\begin{array}{l}\text { Number of } \\
\text { crystallizing } \\
\mathrm{CH}_{2} \text { groups }\end{array}$}} \\
\hline & & & & & & & & & \\
\hline & $T_{\mathrm{m}_{1}}$ & $T_{\mathrm{cr}}$ & $T_{\mathrm{m}_{2}}$ & $\Delta H_{1}$ & $-\Delta H_{\mathrm{cr}}$ & $\Delta H_{2}$ & $n_{1}$ & $n_{\mathrm{cr}}$ & $n_{2}$ \\
\hline [1]-TC & -21 & -32 & -18 & 0.48 & 0.51 & 0.52 & 0.65 & 0.69 & 0.71 \\
\hline$[1]-I C$ & -18 & -30 & -15 & 0.41 & 0.47 & 0.48 & 0.56 & 0.64 & 0.66 \\
\hline [1]-SC & 17 & 3 & 15 & 0.79 & 0.78 & 0.76 & 1.07 & 1.06 & 1.04 \\
\hline [1]-PI & 12 & -1 & 9 & 0.71 & 0.68 & 0.72 & 0.96 & 0.93 & 0.97 \\
\hline$[1[-\mathrm{HI}$ & -5 & -23 & -8 & 0.82 & 0.84 & 0.83 & 1.11 & 1.14 & 1.13 \\
\hline [3] $\mathrm{TC}$ & 58 & 8 & 25 & 5.62 & 4.85 & 4.80 & 2.55 & 2.20 & 2.18 \\
\hline [3]-IC & 57 & -5 & 8 & 4.20 & 5.13 & 5.54 & 1.90 & 2.33 & 2.51 \\
\hline [3]-SC & 58 & 31 & 40 & 8.91 & 7.87 & 7.63 & 4.04 & 3.57 & 3.46 \\
\hline [3]-PA & 59 & 5 & 10 & 6.71 & 5.37 & 5.52 & 3.04 & 2,43 & 2.50 \\
\hline [3]-PI & 64 & 52 & 62 & 7.12 & 5.63 & 5.48 & 3.22 & 2.55 & 2.48 \\
\hline [3]-MI & 62 & 20 & 29 & 6.51 & 6.36 & 6.53 & 2.95 & 2.88 & 2.96 \\
\hline [3]-TI & 60 & 14 & 23 & 6.83 & 6.56 & 6.41 & 3.10 & 2.98 & 2.90 \\
\hline [3]-HI & 44 & 23 & 34 & 7.57 & 7.26 & 7.18 & 3.43 & 3.30 & 3.25 \\
\hline [4]-SC & 64 & 18 & 32 & 7.50 & 7.25 & 7.28 & 3.40 & 3.29 & 3.30 \\
\hline [4]-HI & 70 & 40 & 55 & 9.64 & 8.17 & 7.96 & 4.37 & 3.70 & 3.61 \\
\hline
\end{tabular}

a Measured by DSC at a heating rate of $10^{\circ} \mathrm{C} \mathrm{min}^{-1}$. 
slow. Their melting peaks could not be completely recovered in spite of standing at room temperature over six monthes. The above observations of X-ray diffraction and DSC scanning illustrate the effect of increased mainchain mobility on the development of crystallinity and perfection of crystals.

Typical data for DSC measurements are listed in Table $\mathrm{V}$. The melting and crystallization temperatures $\left(T_{m_{1}}, T_{\mathrm{cr}}\right.$, and $\left.T_{m_{2}}\right)$ were determined by the tops of the DSC peaks. The average numbers of crystallizing $\mathrm{CH}_{2}$ groups in each side-chain $\left(n_{1}, n_{\mathrm{cr}}\right.$, and $\left.n_{2}\right)$ were calculated from the enthalpies of fusion and crystallization $\left(\Delta H_{1}, \Delta H_{\mathrm{cr}}\right.$, and $\left.\Delta H_{2}\right)$ by $735 \mathrm{cal} \mathrm{mol-}$ $\mathrm{CH}_{2}{ }^{-1}$ of $n$-alkanes in hexagonal packing. ${ }^{18}$ The SC- and $\mathrm{HI}-$ polymers containing flexible segments in the main chain gave a higher number of crystallizing $\mathrm{CH}_{2}$ groups than those of the other polymers. The introduction of the aliphatic SC or HI, rather than the other aromatic comonomers, into polymer chain results in a wider spaces between long sidechains. The introduction of the aliphatic SC and $\mathrm{HI}$ also increases the main-chain mobility and allows the side-chains to approach each other. Therefore, the flexibility of main-chain structure for the comb-like polymers may be considered to be an important effect on the side-chain crystallization. Furthermore, in order to make a comparison of crystallinity, the one side-chain polymers were assumed to crystallize also in a hexagonal form. The influence of the number of long alkyl groups in each repeating unit on side-chain crystallization was studied. The crystallinity of the three sidechains polymers was about 3 to 4 times that of the one side-chain polymers, and about 1.5 to 2 times that of the previous two side-chains polymers. $^{7-9)}$

\section{Conclusions}

A series of new type comb-like polymers containing three long alkyl side-chains in each repeating unit were synthesized. For these comb-like polymers with a rigid main-chain, side-chain crystallization was found to occur by DSC and X-ray diffraction. The solubilities of the polymers had an obvious change with increasing number of side-chains in the repeating unit. The number of side-chains in the repeating unit virtually had no effect on the thermal stabilities of the polymers. Crystallinity increased remarkably with the number of side-chains in the repeating unit.

\section{REFERENCES}

1. B. Cayro, A. Eisenberg, J. F. Harrod, and P. Rocaniere, Macromolecules, 5, 677 (1972).

2. S. M. Aharoni, Macromolecules, 12, 94 (1979).

3. M. Takayanagi and T. Katayose, J. Appl. Polym. Sci., 29, 141 (1984).

4. J. Watanabe, H. Ono, I. Uematsu, and A. Abe, Macromolecules, 18, 2141 (1985).

5. F. Andruzzi, C. Barone, D. Lupinacci, and P. L. Magagnini, Makromol. Chem., Rapid Commun., 5 , 603 (1985).

6. J-K. Lin, H. Kunisada, S. Kondo, and Y. Yuki, Kobunshi Ronbunshu, 45, 831 (1988).

7. J-K. Lin, Y. Yuki, H. Kunisada, and S. Kondo, $J$. Appl. Polym. Sci., in press.

8. J-K. Lin, Y. Yuki, H. Kunisada, C. Miyagawa, and S. Kondo, Polym. J., 21, 709 (1989).

9. J-K. Lin, Y. Yuki, H. Kunisada, M. Kondo, and S. Kondo, Polym. J., 22, 54 (1990).

10. Y. Yuki and Y. Osaka, Kobunshi Kagaku, 30, 720 (1973).

11. Y. Yuki, H. Kunisada, and S. Kondo, Kobunshi Ronbunshu, 46, 233 (1989).

12. Y. Yuki and M. Kinoshita, Nippon Kagaku Kaishi, 549 (1977).

13. C. G. Overberger, L. H. Arond, R. H. Wiley, and R. R. Garrett, J. Polym. Sci., 7, 431 (1951).

14. S. A. Greenberg and T. Alfrey, J. Am. Chem. Soc., 76, 6280 (1954).

15. E. F. Jordar, Jr., D. W. Feldeisen, and A. N. Wrigley, J. Polym. Sci., A-1, 9, 1835 (1971).

16. N. A. Platé and V. P. Shibaev, J. Polym. Sci., Macromol. Rev., 8, 117 (1974).

17. D. Chapman, J. Chem. Soc., 4489 (1957).

18. M. G. Broadhurst, J. Res. Natl. Bur. Stand., 66A, 241 (1962). 